\title{
Effects of cutting speed on tool nose wear with ACE-MQL aerosol at optimum-temperature
}

\author{
S. W. M. A. I. Senevirathne ${ }^{1}$, R. K. P. S. Ranaweera ${ }^{2 *}$ \\ ${ }^{1,2}$ Department of Mechanical Engineering, University of Moratuwa, Moratuwa, Sri Lanka
}

\section{Keywords \\ Cutting fluid \\ Machining \\ MQL \\ Tool steels}

Received: 8 January 2018

Accepted: 31 January 2018

Published: 13 February 2018

\begin{abstract}
This study is focused on evaluating newly developed chilled-emulsion Minimum Quantity Lubrication (MQL) method on machining hard-to-cut metals. Previous research work revealed that, aerosol at $15^{\circ} \mathrm{C}$ provides the optimal tool life and generates the least surface roughness when machining AISI P20 and D2 tool steels at a given cutting speed. In that context, the influence of varying cutting speeds with MQL aerosol at $15^{\circ} \mathrm{C}$ is further studied in this paper. Three cutting speeds were used as per the tool manufacturer's recommendations. For the aforementioned cutting conditions, tool nose wear were measured and topologies of worn cutting edges were observed and compared. The experimental results revealed that tool wear rate and other forms of damages such as chipping and plastic deformation for different work material have contrasting responses. This indicates that MQL aerosol performance is notably sensitive to work material properties and its benefits as a cutting fluid should be further investigated over wider range of materials.
\end{abstract}

(C) 2018 The Author(s). Published by TAF Publishing.

\section{INTRODUCTION}

Metal cutting is a popular manufacturing process because of its ability to produce parts with high dimensional accuracy and surface finish. Despite its versatility to produced parts with various shapes and sizes, the inherent drawback of heat generation and associated undesirable effects have been a major concern for decades. Copious amount of heat is generated during machining due to shearing and frictional sliding $[1,2,3]$. The generated heat will adversely influence the cutting forces and power consumption, surface roughness conditions of the cut work-piece, degree of tool failure such as wearing, chipping, etc. There are numerous attempts to mitigate these undesirable issues, but none of the proposed techniques were satisfactory [4]. Typically, a Cutting Fluid (CF) is used to remove heat from the work-piece and cutting tool, and provide lubrication between rubbing faces to minimise heat generation. Emulsion CF is said to be the most commonly used CF, which is applied as a flood over the cutting area [5]. Generally, a metal cutting machines would require around 100 litres of $\mathrm{CF}$ per maintenance cycle, and change of $\mathrm{CF}$ frequently. Expenditure for cutting fluid in the European automotive industry is nearly $20 \%$ of the total manufacturing cost $[6,7]$. The cost of tools was only $7.5 \%$ of the total manufacturing cost, making the cutting fluid cost to be comparatively higher than other costs associated with manufacturing.

In general, $\mathrm{CF}$ are classified based on either method of application or type of fluid used. There are numerous CF applications methods traditionally used by the industry such as high pressure spraying, flooding or dripping, misting, brushing, etc. MQL is a recently developed CF application method mainly targeted to minimize volume of $\mathrm{CF}$ usage while improving cutting efficiency. It has shown significant increase in metal cutting performances under certain operating conditions.

In previous research work, chilled MQL aerosol at $15^{0} \mathrm{C}$ provided the optimal tool life and generated the least surface roughness when machining AISI P20 and D2 tool steels,

\footnotetext{
${ }^{*}$ Corresponding author: R. K. P. S. Ranaweera

†email: pubudu@mech.mrt.ac.lk
} 
which are popular choices of material in the die and toolmaking industry. These are known as hard-to-cut metals, as a result of their superior mechanical properties. However, the aforementioned study only considered MQL aerosol performance at a specific cutting speed. Therefore, the ongoing study attempts to study the influence cutting parameters over different controlled conditions.

\section{A. Objective of the Study}

The study is aimed at investigating the influence of varying cutting speeds with MQL aerosol at $15^{0} \mathrm{C}$ (henceforth referred to as 'optimum temperature') for two different work materials; AISI P20 and D2 tool steels. The nose radius and flank surface deterioration are probed to make inferences on the study.

\section{LITERATURE REVIEW}

MQL, also known as Near-dry machining, has shown significant increase in metal cutting performances under certain conditions. In MQL $[8,9,10]$, a minute amount of cutting fluid is sputtered to the cutting area as an aerosol using high pressure pneumatic supply.

Previous research suggests that MQL provides better surface finish, higher tool life, reduce cutting temperature, and reduce usage of cutting fluids $[11,12,13,14,15]$. However, another research points out that the performances of MQL does depend on numerous factors, such as tool and work material, cutting fluid, aerosol temperature etc $[9,15,16,17]$.

It was pointed that, when milling forged steel, the tool flank wear has been greatly reduced with MQL [15]. They have investigated the effect of nozzle direction, nozzle distance, cutting oil flow rate, and cutting time by studying tool flank wear and work-piece surface roughness. According to [18] as stated by [15], the cutting forces reduces with increasing nozzle pressure. Further, according to (Lutao et al., 2012), the flow rate of the aerosol does not influence the surface roughness and tool wear significantly. As [12] explained, the main benefit of MQL is its ability to reduce surface roughness by lowering the cutting temperature.

An investigation by [19] shows that MQL has given low tool wear and better surface roughness in machining AISI 202 stainless steel using coated carbide tools. A similar observations are seen by [20] when machining AISI P20 and D2 using coated carbide tools. Further, [19] stated that, cutting speed is the most influential predictor, with $49 \%$ influence on tool wear and 70\% influence on Arithmetic Average of Surface Roughness (RA). Moreover, they have concluded that, MQL fluid flow is influential by $40 \%$ on tool wear and
$25 \%$ on RA. However, [21] in their study have mentioned that MQL does create mist more than flood cooling method. According to them, this mist could be hazardous in metal cutting environment due to sparking, and can create health problems as well. They recommend using vegetable oil or synthetic oil instead of mineral oil to avoid these complications.

According to [22], aerosol nozzle orientation plays a vital role on MQL performances. The surface roughness and tangential forces were highest when the aerosol was applied to work-piece surface. Further, they concluded that, the distance to the nozzle is critical to the MQL performance. Although majority of the literature points out the advantages, [23] has mentioned that MQL lacks cooling effect, and flushing cut chip away from the work area. As they explained, due to those reasons, MQL is not a viable for machining hard-to-cut metals as well as drilling or grinding deep-holes. However, [9] have pointed out that cooling effect can be improved by using chilled CF.

[24] concluded that, the position of the aerosol highly effects on the performances of the cutting system. They have studied the cutting force, tool nose and flank wear, and surface roughness, while applying aerosol to the rake face and flank face. Similar to many other researchers, they also claim that, MQL causes improvements in tool life, cutting forces, and surface roughness. In their research [25] have stated that, though MQL has given better results in certain conditions, there are other instances where the MQL system has given poor results than certain popular cooling methods. Similar results were seen by [9]. They have found that, when temperature of the aerosol is varied, under certain temperatures, MQL has given poor results than conventional flood cooling method. Moreover, [26] have observed lower cutting forces with MQL as a result of reduction in cutting temperature. Further, they explained that, reduction in cutting temperature also helped to retain the tool sharpness. They argued that, MQL can reduce the frictional forces, formation of built-up-edge, and thermal distortions occur due to generated heat. Similar results were given in another study [27]. They claimed that, MQL with multiwall carbon nanotube particles has caused a decrease in cutting temperature as well as better surface finish with improved tool life. Another study carried out using MQL method in machining Aluminium found that, presence of Oxygen in the ambient has caused Aluminium to oxidise [28] which is contradictory to findings of many other researchers. [18] have carried out an investigation on AISI 4340 with coated carbide tool, and concluded that MQL parameters such as, nozzle pressure, aerosol pulsation rate, etc. are influential 
heavily on cutting performances.

Reviewing the literature, it can be concluded that, the performances of MQL system depends on many different parameters that spreads across; cutting parameters, work parameters, tool parameters, cutting fluids, to MQL operation parameters and so on. The dependency of MQL performances on work and tool material necessitate that investigation of different work-tool material combinations with MQL method. Further, since it is pointed out in literature that, MQL performance depends on machining parameters such as, depth-of-cut, feed rate, and cutting speed, and MQL parameters such as flow-rate, pneumatic pressure, etc.; their correlation to the outcome needed to be investigated.

\section{METHODOLOGY}

\section{A. Experiment Design}

A custom-made MQL aerosol application apparatus was used for the experiments. This apparatus comprises of MQL cooling system and MQL delivery system. The details of the design is presented in [29]. Figure 1 shows the MQL cooing system comprised of AC or refrigeration unit, coolant tank for $\mathrm{CF}$, evaporator to cool $\mathrm{CF}$, temperature controller and $\mathrm{CF}$ line to deliver chilled MQL to the spray gun.

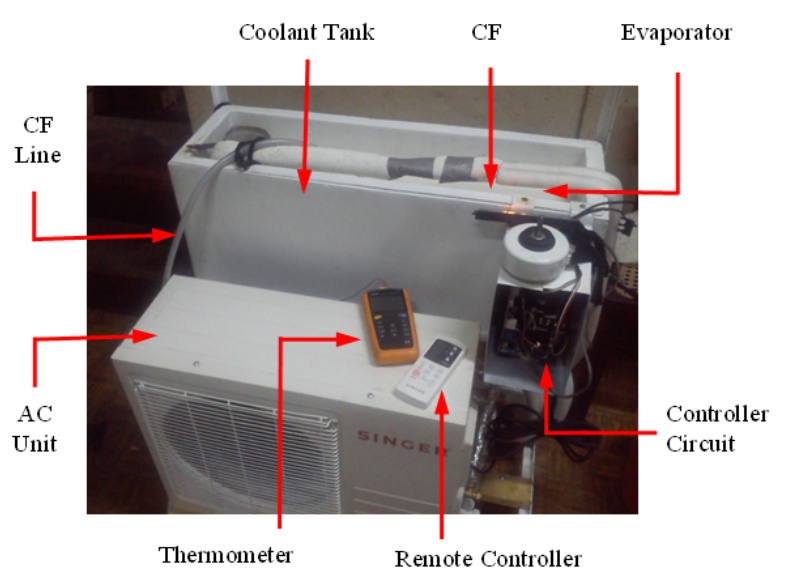

Fig. 1. MQL cooling system

The chilled MQL is delivered to the cutting zone using spray gun as shown in Figure 2. Note that complete MQL delivery system includes the air compressor and spray gun kit. During the experiment, a continuous flow of chilled MQL is obtained using a full-cone spray nozzle. The spray pattern from the experiments is further illustrated in Figure 2.

Following a thorough literature review, a preliminary set of parameters were selected for the experiment. These pa- rameters are further refined after a pilot experiment. The Tool Nose Radius (TNR) was taken as the response variable. The results of the pilot trials were also used to further refine the experiment parameters. A two-level factorial experiment was designed [30]. AISI P20 and AISI D2 work-piece materials were taken as the first level. Three surface cutting speeds were taken as the second level as illustrated in Figure 3. 


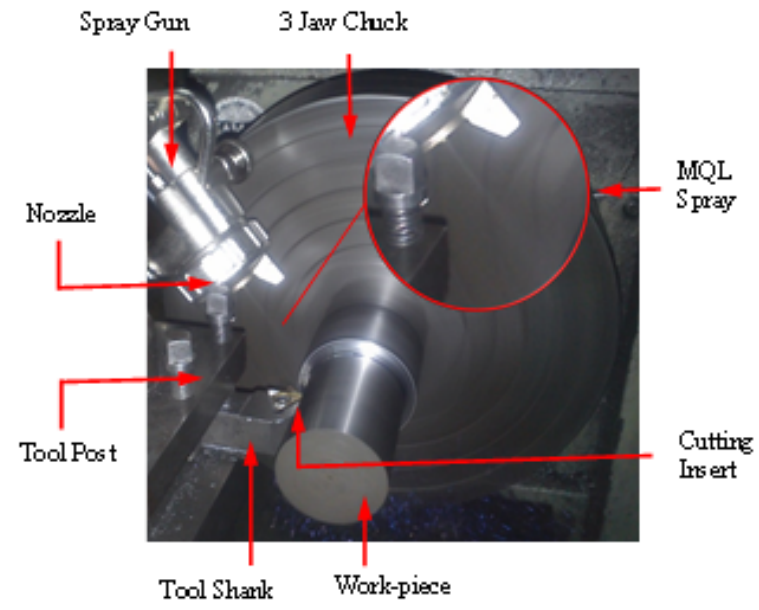

Fig. 2. Application of chilled MQL

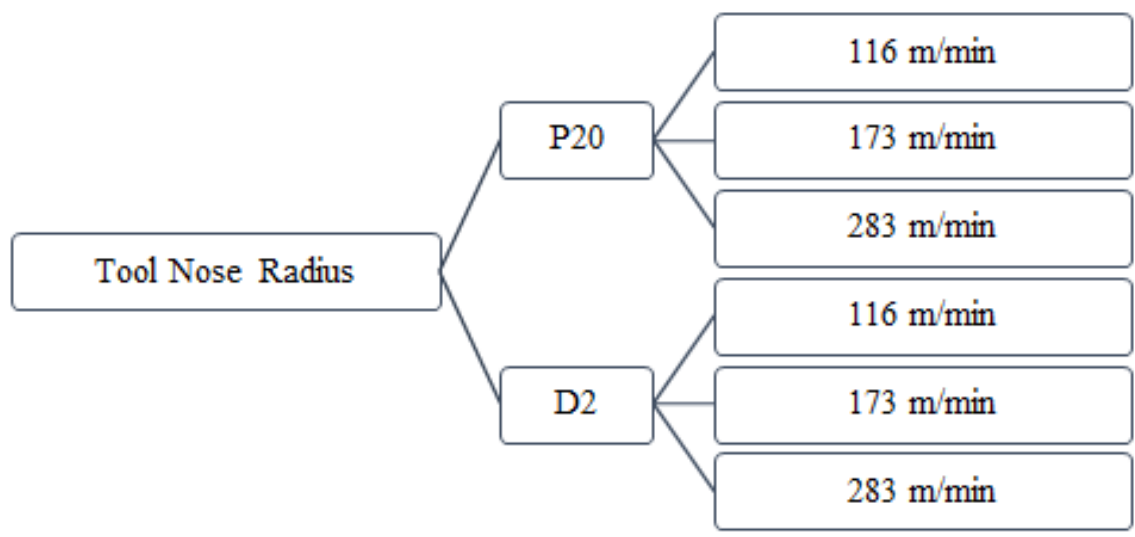

Fig. 3. Schedule of experiments

\section{B. Experimental Setup}

The controlled parameters for the experiment are given in Table 1. Considering the necessity of comparison of results with past research, simplicity of the machining operation, and ease of operation, straight turning operation was used for the study. Feed rate and depth of cut were selected based on the tool manufacturers' recommendation and by reviewing related literature. Spindle speeds are also chosen following the tool manufacturers' recommendation to determine the surface cutting speed. Length of the cut was determined by the results of the pilot run. MQL aerosol flow rate, pneumatic pressure, nozzle target location and nozzle direction are selected based on the literature review data.

TABLE 1

CONTROLLED PARAMETERS OF EXPERIMENTS

\begin{tabular}{llll}
\hline \hline Parameter & Value & Parameter & Value \\
\hline Turning operation & Straight & Flow Rate (MQL) & $160 \mathrm{ml} /$ hour \\
Feed rate & $0.3 \mathrm{~mm} / \mathrm{rev}$ & Pneumatic Pressure & $7 \mathrm{bar}$ \\
Depth of cut & $0.5 \mathrm{~mm}$ & Flow Rate (Flood) & $9 \mathrm{l} / \mathrm{min}$ \\
Cutting length & $500 \mathrm{~mm}$ & Nozzle Target Area & Rake face \\
Surface cutting speed & $150 \mathrm{~m} / \mathrm{min}$ & Nozzle Angle $(\mathrm{H})$ & $\approx 60^{0}$ \\
Aerosol temperature & $15{ }^{0} \mathrm{C}$ & Nozzle Distance & $150 \mathrm{~mm}$ \\
\hline \hline
\end{tabular}


Simple straight turning operation was performed using a $3.0 \mathrm{~kW}$ lathe machine; model no. Colchester Bantam 2000. Nine pieces from each of AISI P20 and D2 tool steels (18 in total) were used for the turning trials. The cylindrical workpieces prepared for the experiments were $45 \mathrm{~mm}$ in diameter and $100 \mathrm{~mm}$ in length. Cutting was performed over ten passes of $50 \mathrm{~mm}$ each, therefore the total cutting length was $500 \mathrm{~mm}$. Turning tool inserts from a prevalent commercial brand that has Chemical Vapour Deposition (CVD) coating were used to machine both types of work-piece materials. These coated carbide tools have coatings of TiCN-Al203-Ti with a hardness of 90.3 HRA. Figure 4 illustrates the dimensions and geometry of the cutting insert used for the trails. Both work-pieces and used cutting tool are marked with a unique identification tag after each trial. Work-pieces were then dipped in emulsion and wrapped with foils to minimise the effect of corrosion, physical damage, and contamination of the machined surface for subsequent use. The same procedure was followed in every trial.

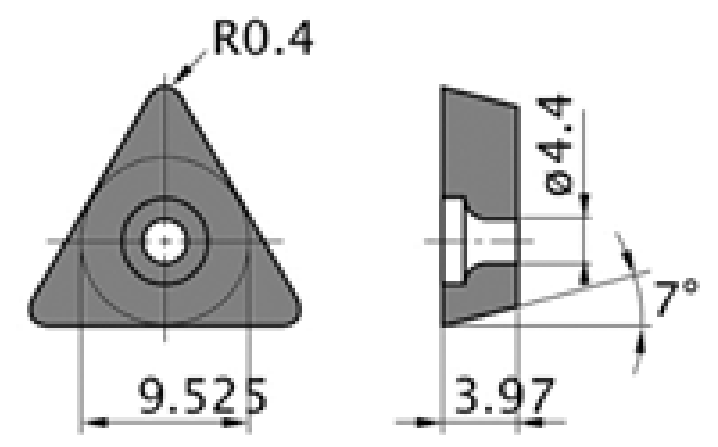

Fig. 4. Geometry of cutting inserts used for experiments (Source - MITSIBISHI Materials-Turning Tool Catalogue) 
As per the CF manufacturer recommendation, CF was prepared to a volumetric ratio 1:9 of emulsion oil to water. The aerosol ejection nozzle is pointed to the rake face of the tool, towards the cutting point, with an inclination to the horizontal by $60^{\circ}$. The MQL delivery direction is shown in Figure 5 in 3-dimensional (3D) space using arrowheads. The nozzle was calibrated empirically to eject $\mathrm{CF}$ at volumetric rate of $160 \mathrm{ml} / \mathrm{hr}$ under pneumatic pressure of $7 \mathrm{bar}$, and the nozzle orifice diameter is $1.2 \mathrm{~mm}$.
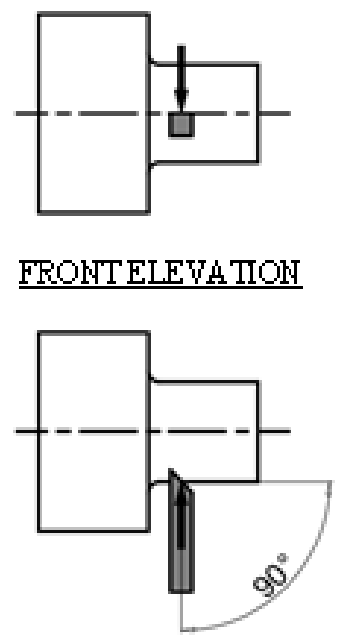

PLAS

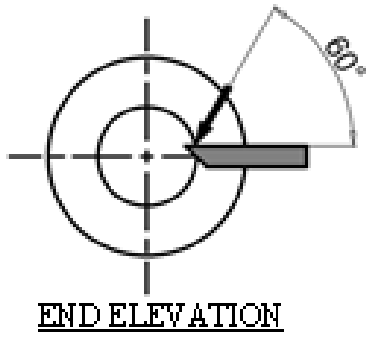

Fig. 5. Nozzle target for MQL delivery
The calibration is done by measuring the time taken to spray a prescribed quantity of CF. Using the apparatus, a heavy concentration of spray is obtained in a circular shape. This necessarily ensures that the MQL is transferred evenly over the target area, which is the entire cut length selected for the experiment.

\section{Predictor and Response Variables}

As predictor variables for the study, three cutting speeds; $V_{i}$ $=116 \mathrm{~mm} / \mathrm{min}, V_{i i}=173 \mathrm{~mm} / \mathrm{min}$, and $V_{i i i}=283 \mathrm{~mm} / \mathrm{min}$, were selected. The selection was mainly based on tool manufacturers' recommendations and findings of the literature review. Only three cutting speeds were selected as the lathe machine used the for the experiment support only three operating speeds.

The TNR was selected as the response variable of the study. Before and after performing cutting operations the tool radii were measured for each of the cutting edges. In a previous study by [9], the distance between the outer edge of the tool nose and a reference point of a specially designed jig was used for determining the nose wear. However in the ongoing study, the TNR was measured using an improvised protocol. The used method directly correlates to standard practices in measuring tool nose wear. Figure 6 shows the procedure followed in determining the TNR with a Computer Numerical Control (CNC) Coordinate Measuring Machine (CMM); model no. De Meet 443. The working accuracy or least resolution of the machine is $0.0001 \mathrm{~mm}$.

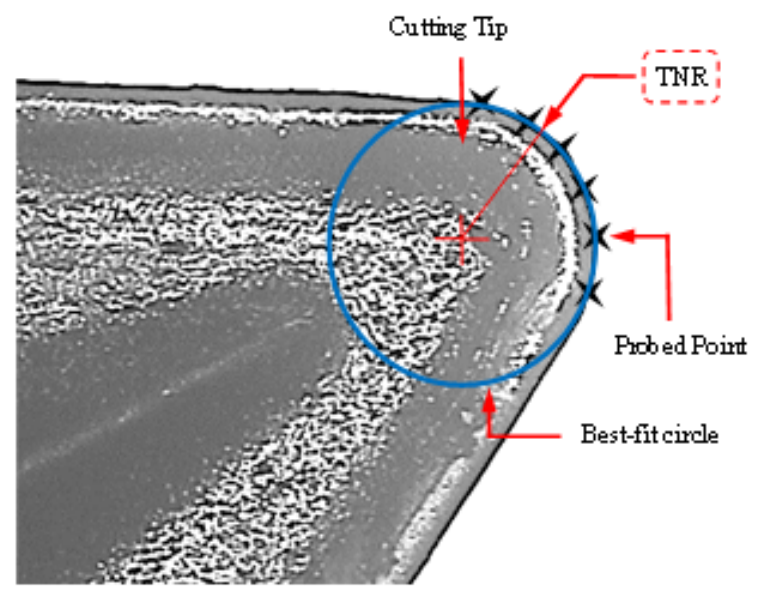

Fig. 6. Protocol to measure TNR

The CMM was fitted with 80X optical lens which was then used to perform non-tactile measurement of the TNR. A best fit-circle was obtained by probing several points over the cutting edge. The outer periphery of the cutting edge was realized by the contrast difference between background and the tool. Number of probed points per measurement were four to six on average. The measurements were repeated three times to minimise human error in judgement. The high resolution images of the cutting edges were separately saved for comparisons. 


\section{RESULTS AND DISCUSSION}

This section presents the results and discussion of the experiments conducted in the study. The tool nose radii were measured before and after the experiments. The unused cutting tips were measured to be equal to $0.4 \mathrm{~mm}$ on average. The TNR variation and their differences are compared to identify possible trends and patterns of the physical phenomenon when using chilled MQL at $15^{\circ} \mathrm{C}$ during turning operation. Here, the details are included under two sub- sections representing effect of cutting speed on tool nose wear and effect of work-piece material on too nose wear.

\section{A. Effect of Cutting Speed on Tool Nose Wear AISI P2O}

The variation of TNR after machining AISI P20 is given in Table 2 . When the surface cutting speed was varied from 116 to $283 \mathrm{~m} / \mathrm{min}$, the difference between final and initial tool nose radii or $\Delta$ TNR were seen increasing slightly. Graphically the phenomenon is illustrated in Figure 7.

TABLE 2

TNR AFTER MACHINING AISI P20

\begin{tabular}{ll}
\hline \hline Surface Cutting Speed (m/min) & Final TNR (mm) \\
\hline 116 & 0.4164 \\
173 & 0.4169 \\
283 & 0.4172 \\
\hline \hline
\end{tabular}

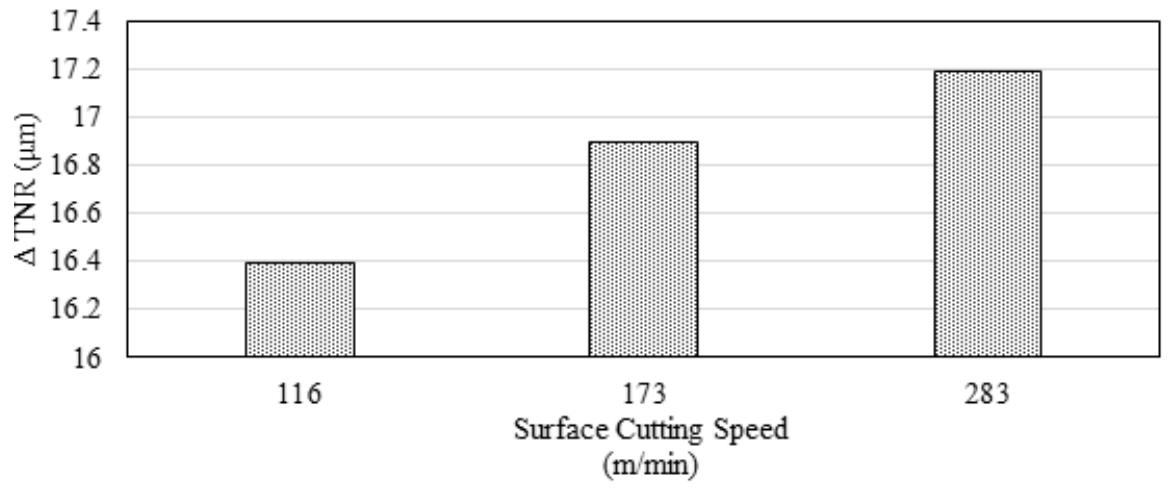

Fig. 7. TNR variation for AISI P20 with increasing cutting speeds

For AISI P20, while applying MQL at $15^{0} \mathrm{C}$, tool nose wear was found to be increasing with increasing cutting speed. The tools were subjected to various types of damages including chipping and plastic deformation. The Figure 8 shows the condition of the rake face of the tool tips for dif- ferent cutting speeds. In addition to tool nose wear, the various damages to the cutting edges are clearly visible at $80 \mathrm{X}$ magnification. However, cutting edges still appear to be usable.
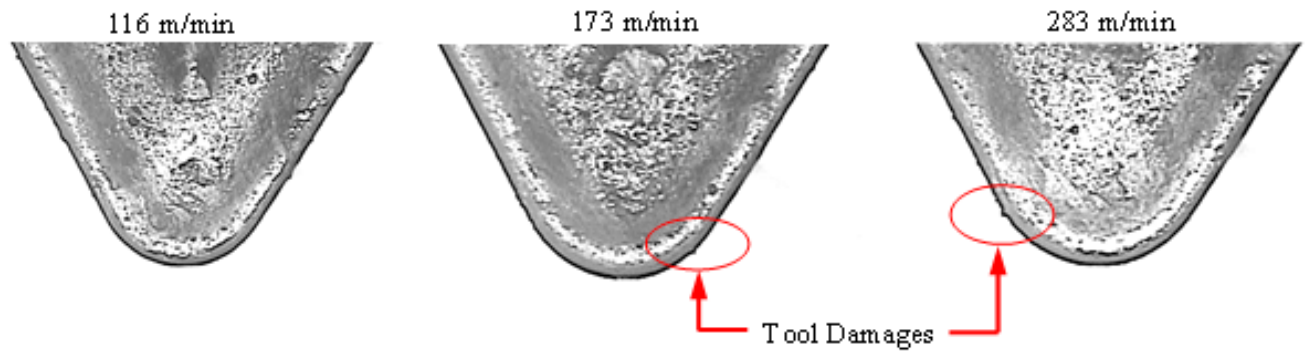

Fig. 8. Tool damages at different cutting speeds for AISI P20 
TABLE 3

TNR AFTER MACHINING AISI D2

\begin{tabular}{ll}
\hline \hline Surface Cutting Speed (m/min) & Final TNR (mm) \\
\hline 116 & 0.4164 \\
173 & 0.4131 \\
283 & 0.4112 \\
\hline \hline
\end{tabular}

The variation of TNR of D2 is given in Table 3 . When the surface cutting speed was varied from 116 to $283 \mathrm{~m} / \mathrm{min}$, the difference between final and initial tool nose radii or $\Delta$
TNR were seen decreasing slightly. Graphical illustration of the same is shown in Figure 9.

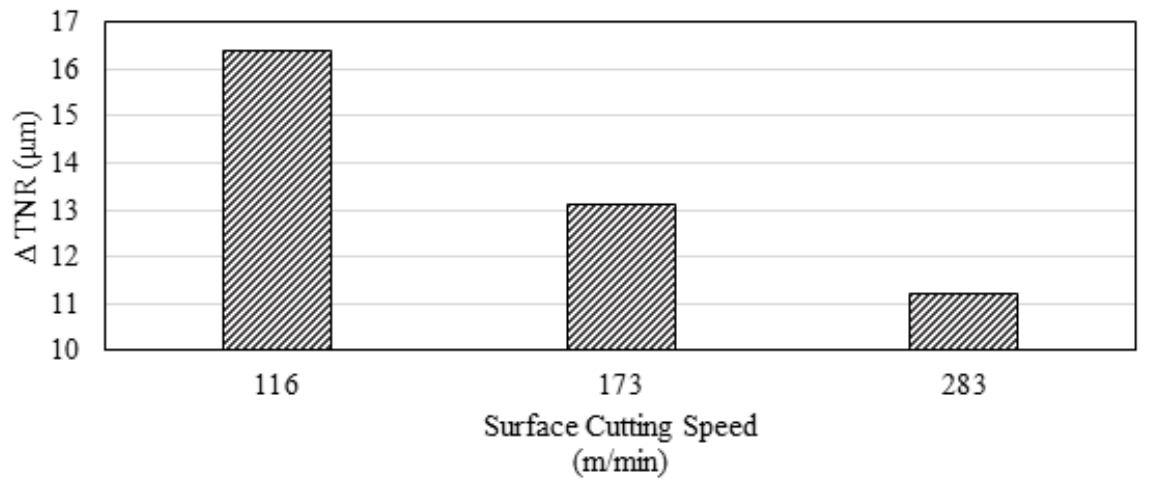

Fig. 9. TNR variation for AISI D2 with increasing cutting speeds

For AISI D2, while applying MQL at $15^{\circ} \mathrm{C}$, tool nose wear is found to be decreasing with increasing cutting speed. Similarly, Figure 10 shows the condition of the rake face of the tool tips for different cutting speeds. In comparison to tool damages noted with P20 material, the frequency of occurrence and magnitude of damages when machining D2 material is found to be higher in general.
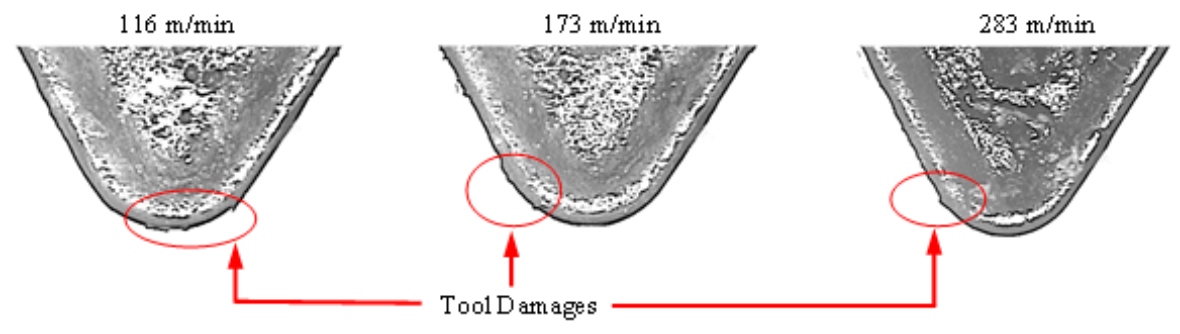

Fig. 10. Tool damages at different cutting speeds for D2

\section{B. Effect of Work Material on Tool Nose Wear}

According to Table 4 and graphical illustration Shown in Figure 11 at $116 \mathrm{~m} / \mathrm{min}$, both material showed the same amount of difference in tool nose radius. However, at 173 $\mathrm{m} / \mathrm{min}$ surface cutting speed, TNR difference in P20 was increased while that of D2 was drastically reduced. The same trend was seen when the speed was increased to $283 \mathrm{~m} / \mathrm{min}$ from $173 \mathrm{~m} / \mathrm{min}$.

TABLE 4

COMPARISON OF TNR AFTER MACHINING AISI P20 AND D2

\begin{tabular}{lll}
\hline \hline Surface Cutting Speed $(\mathrm{m} / \mathrm{min})$ & AISI P20 $(\mu \mathrm{m})$ & AISI D2 $(\mu \mathrm{m})$ \\
\hline 116 & 16.4 & 16.4 \\
173 & 16.9 & 13.1 \\
283 & 17.2 & 11.2 \\
\hline \hline
\end{tabular}




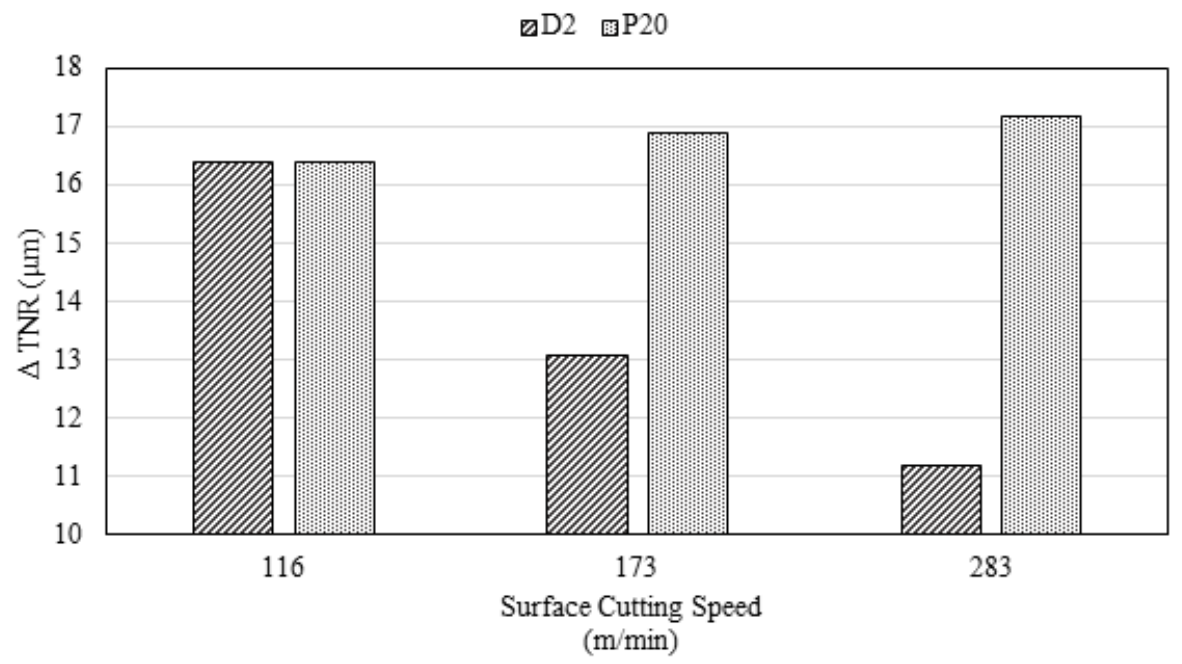

Fig. 11. Comparison of TNR variation for different work-materials

\section{CONCLUSION}

The MQL aerosol performance is found to be sensitive to both cutting speed and work material properties. In particular, with increasing cutting speed, tool wear is noted with varying rates. For AISI P20 and D2 work materials, tool wear rate appears to be increasing and decreasing respectively. However, when comparing other forms of damages including chipping and plastic deformation of cutting edges, D2 material has had a harsh impact on the tools than the P20 material. The experiments were only limited to two commonly used materials in the tool-making industry. However, as future work, empirical data for different work material should be gathered and compared to determine the performance of chilled MQL at the optimum temperature. It is recommended to evaluate both tool wear and failure to determine the effective tool life.

\section{ACKNOWLEDGEMENT}

The authors wish to extend their gratitude to Mr KHJ Mangala, Mr IMJ Priyankara and other technical staff attached to Die and Mould Facilitation Center in Department of Mechanical Engineering at University of Moratuwa, Sri Lanka for providing technical assistance to conduct the experiments.

\section{REFERENCES}

[1] N. Abukhshim, P. Mativenga, and M. Sheikh, "Heat generation and temperature prediction in metal cutting: A review and implications for high speed machining," International Journal of Machine Tools and Manufacture, vol. 46, no. 7-8, pp. 782-800, 2006. doi: 10.1016/j.ijmachtools.2005.07.024

[2] S. Kalpakjian and S. R. Schmid, Manufacturing Processes for Engineering Materials. New York, NY: Pearson Education Inc, 2016.

[3] R. Komanduri and Z. B. Hou, "Thermal modeling of the metal cutting process part iii: Temperature rise distribution due to the combined effects of shear plane heat source and the tool chip interface frictional heat source," International Journal of Mechanical Sciences, vol. 43, no. 1, pp. 89-107, 2001. doi: 10.1016/s0020-7403(99)00104-6

[4] S. Senevirathne and H. Punchihewa, "Reducing surface roughness by varying aerosol temperature with minimum quantity lubrication in machining AISI P20 and D2 steels," The International Journal of Advanced Manufacturing Technology, vol. 94, no. 1-4, pp. 1009-1019, 2018. doi: 10.1007/s00170-017-0951-4

[5] E. Brinksmeier, M. Garbrecht, C. Heinzel, T. Koch, and J. Eckebrecht, "Current approaches in design and supply of metalworking fluids," Tribology Transactions, vol. 52, no. 5, pp. 591-601, 2009. doi: 10.1080/10402000902825739

[6] M. Abduelmula, M. Birkett, and C. Connor, "A mixed method approach to investigate the lack of lean manufacturing implementation in Libya ]," International Journal of Technology and Engineering Studies, vol. 3, no. 3, pp. 111-116, 2017. doi: 10.20469/ijtes.3.40003-3

[7] T. Brockhoff and A. Walter, "Fluid minimization in cutting and grinding," Abrasives, Journal of Abrasives Engineering Society, vol. 10, no. 11, pp. 38-42, 1998. doi: 10.1299/jsmelem.2013.7.79

[8] S. Y. Liang and A. Ronan, Minimum Quantity Lubrication in Finish Hard Turning, Atlanta, GA, 2003. 
[9] S. Senevirathne and H. Punchihewa, "Effect of minimum quantity lubrication aerosol temperature on tool life in machining aisi p20 and d2 steels using coated tungsten carbide tool inserts," in Moratuwa Engineering Research Conference, Moratuwa, Sri Lanka, 2016.

[10] K. Weinert, I. Inasaki, J. Sutherland, and T. Wakabayashi, "Dry machining and minimum quantity lubrication," CIRP Annals-Manufacturing Technology, vol. 53, no. 2, pp. 511-537, 2004. doi: 10.1016/s0007-8506(07)60027-4

[11] N. Dhar, M. Kamruzzaman, and M. Ahmed, "Effect of Minimum Quantity Lubrication (MQL) on tool wear and surface roughness in turning AISI-4340 steel," Journal of Materials Processing Technology, vol. 172, no. 2, pp. 299-304, 2006. doi: 10.1016/j.jmatprotec.2005.09.022

[12] S. Kedare, D. Borse, and P. Shahane, "Effect of Minimum Quantity Lubrication (MQL) on surface roughness of mild steel of 15HRC on universal milling machine," Procedia Materials Science, vol. 6, pp. 150-153, 2014. doi: 10.1016/j.mspro. 2014.07.018

[13] J. H. Lee, S. P. Kim, and R. W. Jeon, "Optimal design for adiabatic pipes using vacuum at cryogenic temperatures," Journal of Advances in Technology and Engineering Research, vol. 2, no. 2, pp. 6-11, 2016. doi: 10.20474/-jater2.1.2

[14] V. S. Sharma, G. Singh, and K. Sørby, "A review on minimum quantity lubrication for machining processes," Materials and Manufacturing Processes, vol. 30, no. 8, pp. 935-953, 2015. doi: 10.1080/10426914.2014.994759

[15] L. Yan, S. Yuan, and Q. Liu, "Influence of minimum quantity lubrication parameters on tool wear and surface roughness in milling of forged steel," Chinese Journal of Mechanical Engineering, vol. 25, no. 3, pp. 419-429, 2012. doi: 10.3901/ cjme.2012.03.419

[16] P. Netake and S. Chinchanikar, "Hard turning under minimum quantity lubrication: Modeling of cutting force and surface roughness," Journal of Advanced Engineering Research, vol. 2, no. 1, pp. 17-22, 2015. doi: 10.1016/j.measurement. 2014.06.002

[17] Q.-C. Hsu et al., "Optimization of minimum quantity lubricant conditions and cutting parameters in hard milling of AISI H13 steel," Applied Sciences, vol. 6, no. 3, pp. 83-90, 2016. doi: 10.3390/app6030083

[18] C. R. V. Kumar and B. Ramamoorthy, "Performance of coated tools during hard turning under minimum fluid application," Journal of Materials Processing Technology, vol. 185, no. 1-3, pp. 210-216, 2007. doi: 10.1016/j.jmatprotec.2006. 03.148

[19] J. Dureja, R. Singh, T. Singh, P. Singh, M. Dogra, and M. S. Bhatti, "Performance evaluation of coated carbide tool in machining of stainless steel (AISI 202) under Minimum Quantity Lubrication (MQL)," International Journal of Precision Engineering and Manufacturing-Green Technology, vol. 2, no. 2, pp. 123-129, 2015. doi: 10.1007/s40684-015-0016-9

[20] S. Senevirathne and H. Punchihewa, "Comparison of tool life and surface roughness with MQL, flood cooling, and dry cutting conditions with p20 and d2 steel," in IOP Conference Series: Materials Science and Engineering. Singapore: IOP Publishing, 2017.

[21] N. Boubekri and V. Shaikh, "Minimum Quantity Lubrication (MQL) in machining: Benefits and drawbacks," Journal of Industrial and Intelligent Information, vol. 3, no. 3, pp. 45-50, 2015. doi: 10.12720/jiii.3.3.205-209

[22] T. Tawakoli, M. Hadad, and M. Sadeghi, "Influence of oil mist parameters on minimum quantity lubrication MQL grinding process," International Journal of Machine Tools and Manufacture, vol. 50, no. 6, pp. 521-531, 2010. doi: 10.1016/j.ijmachtools.2010.03.005

[23] B. L. Tai, D. A. Stephenson, R. J. Furness, and A. J. Shih, "Minimum Quantity Lubrication (MQL) in automotive powertrain machining," Procedia CIRP, vol. 14, pp. 523-528, 2014. doi: 10.1016/j.procir.2014.03.044

[24] M. Hadad and B. Sadeghi, "Minimum Quantity Lubrication-MQL turning of AISI 4140 steel alloy," Journal of Cleaner Production, vol. 54, pp. 332-343, 2013. doi: 10.1016/j.jclepro.2013.05.011

[25] D. Carou, E. M. Rubio, and J. P. Davim, "A note on the use of the Minimum Quantity Lubrication (MQL) system in turning," Industrial Lubrication and Tribology, vol. 67, no. 3, pp. 256-261, 2015. doi: 10.1108/ilt-07-2014-0070

[26] N. Dhar, M. Ahmed, and S. Islam, “An experimental investigation on effect of minimum quantity lubrication in machining AISI 1040 steel," International Journal of Machine Tools and Manufacture, vol. 47, no. 5, pp. 748-753, 2007. doi: 10. 1016/j.ijmachtools.2006.09.017

[27] P. Sharma, B. S. Sidhu, and J. Sharma, "Investigation of effects of nanofluids on turning of AISI D2 steel using minimum quantity lubrication," Journal of Cleaner Production, vol. 108, pp. 72-79, 2015. doi: 10.1016/j.jclepro.2015.07.122

[28] T. Wakabayashi, S. Suda, I. Inasaki, K. Terasaka, Y. Musha, and Y. Toda, “'Tribological action and cutting performance of 
MQL media in machining of aluminum," CIRP Annals-Manufacturing Technology, vol. 56, no. 1, pp. 97-100, 2007. doi: 10.1016/j.cirp.2007.05.025

[29] S. W. M. A. I. Senevirathne, "Effect of Air and Chilled Emulsion Minimum Quantity Lubrication (ACEMQL) in machining hard to cut metals," Ph.D. dissertation, University of Moratuwa, Moratuwa, Sri Lanka, 2015.

[30] D. C. Montgomery, Design and Analysis of Experiments. New York, NY: John Wiley \& Sons, 2017. 